\title{
Reflection on Higher Education in the Arts in Mainland China: An Opportunity to Promote Artists Personal Development?
}

\author{
Yan $\mathrm{Su}^{1}$ \\ ${ }^{1}$ The Hong Kong Institute of Education, Hong Kong \\ Correspondence: Yan Su, The Hong Kong Institute of Education, Hong Kong. The Hong Kong Institute of \\ Education ranked 3rd in Asia and 15th in the world in Education (QS World University Rankings by Subject \\ 2015).E-mail: ysu1988@gmail.com
}

\author{
Received: October 19, 2015 Accepted: November 16, 2015 Online Published: November 27, 2015 \\ doi:10.5539/ass.v11n28p221 URL: http://dx.doi.org/10.5539/ass.v11n28p221
}

\begin{abstract}
Since 1990, the discourse of educational universalization has been a prominent feature of reform. Specifically, the Chinese government supported arts reform in 2000. Drawing on policy documents produced by the higher education segment of the Ministry of Education (MOE), this paper analyses the historical teaching model, presenting key challenges and implications for higher education in mainland China, in reference to current concerns.
\end{abstract}

\section{Background}

Chinese culture has a long history, heavily influenced by a Confucian outlook on politics and education. Confucianism promotes social liquidity and equity, by advocating the belief that if a good scholar is encouraged through education, ordinary people will be motivated to pursue official careers through learning. A hundred years ago China adopted modern educational practices from the West. Firstly, it drew on the experiences of Japan, and then began to imitate the German education system. Thus, China's modern education has followed a traditional approach (Guan, 2013). China went on to apply features of the American education system in 1922, and Dewey lectured in China between 1919 and 1921. However, China's education system remained traditionalist. The Soviet Union had the greatest impact on Chinese education prior to the foundation of new China in 1949 (Guo, 2004). The Soviet education system was discipline-oriented, and it retains a significant influence on Chinese education to date. Objectively speaking, this system sought to analyze educational phenomena by applying the tenets of Marxism. These mirrored many of the collectivist values and characteristics of the Confucian approach to education. However, in contrast, artistic achievements evoke a cultural tradition that privileges education for self-improvement and family honor. This is important as Chinese parents set higher educational goals and standards for their children than Western parents do (Brand, 2002). Indeed, family orientation, cultural values, and other societal pressures account for many of the differences between Chinese and Western cultures.

It is widely accepted that emphasis on education and knowledge accelerates social cultural development (Wang, 1995). Development advances by attainment of both systematic scientific and cultural knowledge and rudimentary knowledge and skills. However, ignorance of students' subjectivity and development, and the absence of a model to cultivate talent and innovation, characterize Chinese higher education practices. Chinese education policy, in line with politics, is based on uniform plans. Evaluative examinations also remain unchanged, although new curriculum reform is introducing some flexibility, providing space for the development of local curricular and school-based curricular, while maintaining uniformity. As Chinese traditional education practice tends to place students in a passive position, students commonly lack enthusiasm to learn and feel powerless in their choice of study (Guan, 2013). Such an underpowered student body is detrimental to talent cultivation.

Since it pursued a policy of opening up and implementing free market reforms in 1979, China's education system has become highly specialized, with many universities expanding, or merging with others, to provide a more comprehensive education in parallel with specialized technical training. However, the entire social environment is characterized by a utilitarianism, which upholds the idea that learning is superior to anything else. Alongside utilitarianism, credentialism has the largest influence on imperial examination systems in Chinese society. In the cultural context of China, utilitarianism places self-interest above other human beings. This 
outlook not only hides a slew of talents within the student body by imposing superior judgments and quashing creative spirit, but it also fosters an educational practice that results in a strong desire for excellence and poor reaction to failure.

The Chinese government is in the process of adapting to the trends of educational universalization, as evidenced in its newly advocated arts policy (Guo, 2012). Henceforth, arts instructors and educators are to be encouraged not only to recognize and value talent, but also to develop students' artisanship, and promote adaptability in their career development (MOE, 2008). As indicated in the introductory section, the concept of "professional training" is one of the most serious concerns of twenty-first century education systems, which seek to shape the personal qualities required to thrive in a new age. Actually, current professional arts training is non-professional due to ill-defined classification of disciplines. Four types of institute offer arts majors in mainland China; Table 1 presents each types of each institute respectively. The training in normal universities and other types of institutes typically follow the conservatory mode. This means, instructors must pay more attention to professional training and classical arts than other kinds of performance and artistic pieces.

Table 1. Four types of arts institutes in mainland China

\begin{tabular}{ll}
\hline Type of Institute & Training Objectives \\
\hline Conservatory & Performers and scholars \\
Normal education & Primary and middle school teacher \\
Pre-school education & Kindergarten teacher \\
Social education & To provide artisan services for society \\
\hline
\end{tabular}

Because of the centralized system in mainland China, the higher education model is similar across all arts institutes. Specifically, superior universities have established a model of teaching that other subordinate universities can imitate. Therefore, the implementation of new policies and principles usually takes place at top-level universities in Beijing or Shanghai. The syllabus for arts education is designed for arts majors, and includes the teaching aims, teaching requirements, course content and hours allocated. This paper seeks to contribute to this growing body of literature by presenting a discourse analysis of the main curriculum syllabus. Specifically, it analyzes the current discourse regarding arts education principles and its production throughout the documents.

\subsection{Objectives}

Students need to learn and understand aesthetic theory, the relationship between aesthetic and educational policies, the historical development of arts (Western history also) and the variety of arts pedagogies, taught in arts education programs in China and abroad. To enable students to gain knowledge of arts pedagogy, they will also be taught research skills, perception of aesthetic responses, and a variety of theories.

\subsection{Requirements}

Students will be expected to develop a basic level of knowledge and critical thinking. Classes will also be opened up for students to ensure reform policies are extended into primary and secondary schools, where general education and theoretical pedagogies will be studied (MOE, 2008).

\subsection{Principal Teaching Content and Time Distribution}

Pedagogy will be taught in foundational classes divided into two parts, one being classes taught (30 credits) systematically by instructors (including Chinese ancient arts education (6 credits), Chinese modern arts education (6 credits), American arts education (6 credits), philosophy of arts education (6 credits); and the second, a final course taught specifically according to selected dominant themes, which will include aesthetic education (6 credits), and arts education research in Chinese primary and secondary schools.

\subsection{Textbooks}

Textbooks are designed to focus on learning-related teaching and curriculum theory; teaching practice to link new curriculum reform in art education, learn arts theory and art courses, by teaching basic concepts, values, theoretical course objectives, teaching practice and lesson plans, and other aspects of methods design, so that students have initial knowledge of literacy teaching theory and research. Research topics will be taught and combined with research to provide teaching cases. This will enable students to access the basic concepts of arts 
and art courses, course objectives and content, the basic model of instruction, teaching methods, teaching organization, teaching evaluation, and curriculum resources. The textbooks will aim to convey certain understandings and awareness, combined with arts and art classes for a fresh interpretation of teaching practice and research.

\subsection{Assessment}

Instructors' will select a major previously introduced issue, and the student(s) will be expected to give a presentation. The commonest assessment approach involves an examination or quiz, in which instructors provide relevant questions in advance, and students simply follow guidelines, read books, perform literature reviews, memorize information and then submit a paper in class. In addition, those instructors responsible for the teaching activity will design some teaching cases, and then students individually, or with a partner, will have to prepare relevant teaching materials including a teaching plan, teaching tools, equipment, curriculum and other resources.

Professional development requires that arts majors' programs conform to the demands of educational universalization in higher education; the policy inevitably led to increased enrollment immediately following its introduction. Universalization requires educators to prepare arts majors to develop general arts classes and performance skills, which include knowledge of arts theory, historical knowledge of Western and Chinese artistic development, composition, instrument performance skills and Kodaly, Orff teaching strategies for arts educators. Although the mission of professional arts educators is to enable artists to work intelligently and creatively in their own areas of interests, instructors are committed to helping students reach a high level of artistic and intellectual development, as their professional training is still the focus of performance-centered arts theory only. For example, rather than seeking to enhance their artistry, some instructors push students to engage in competitive performance and composition. As a result, students' understanding of social benefits leads to conflicts drawn from their supervisors, which inform their personal development. Therefore, this paper argues that there are a number of challenges that need to be overcome to enhance mainland China arts reforms and leaders enactment of the same.

\section{Current Challenges in Higher Education}

Before the introduction of a mainland Chinese policy supporting reform of the arts, research suggested the government should address the need to develop arts education, in line with moral education and aesthetic education. Proposals included introducing the teaching of a series of folk songs, and providing a public opera repertoire for students in higher education. The suggestions outlined above for programs were articulated in the policy documents. However, according to the National Career Report (2010) a low rate of employment afflicts arts, performance, radio hosting, and other artistic specializations. The most pressing issues highlighted by social reports include sharp rises in enrollment. In addition, the reports identified a number of issues, including the absence of a moral educational component, an obsolete teaching model, policy inadequacies, and a lack of opportunities for skills enhancement for staff and unsatisfactory employment status. These denunciations, based on discontent with the progress of national reform movements, impelled the establishment of national and statutory policy documents for higher education in mainland China.

\subsection{Lack of a Student-Centered Training Model}

At this time, arts educators in Chinese mainland contend that arts education should afford students a better understanding of the arts. They take relative novices and familiarize them with arts related culture and content. Teaching assessment identifies the amount of knowledge students have acquired from teachers as a criterion. In the teaching model, the teacher plays a dominant role, while students follow the teacher's dictates obediently, often losing their enthusiasm for learning. In this context, students learn that imitation is the right way to acquire knowledge, consider copying the optimal method, and measure the amount of knowledge they can indiscriminately imitate to determine the standard of their learning. Arts teaching methods, treating arts textbooks as a chief source, reflect a series of different teaching activities that can enhance students' aesthetic ability and help them develop their elementary skills and knowledge. Arts teaching methods can be divided into two types; the methods written in textbooks based on teaching content and the practical methods displayed while teaching.

A large number of students have enrolled in arts departments since 2000; thus, test scores are now employed to measure students' performance. For this reason, many arts majors have gradually lost interest and confidence in learning, distorting their professional training. Once the goals of professional training were established, instructors introduced a Western mode of training into Chinese artisans. There exists a long known dilemma in which arts majors feel they must be either a performer on the stage or a teacher in a class. Additionally, internship classes are available to senior students for only $4-5 \%$ of the time allocated in the schedule, which is 
far less than the 25\% level in American and European countries. Social needs are a prerequisite for professional development for arts graduates; however, university arts faculties offer "professional thinking" largely immersed in arts knowledge itself. Pop art is becoming mainstream in social life and professional training, largely born out of Western classical arts. Therefore, arts graduates find it a challenge to meet the diverse needs of modern society.

For many teachers, apprenticeships within an oral tradition were the means by which they received knowledge and skills. Coming from such a background, teachers have a superior ability to impart this knowledge. Expository teaching takes the form of statement and explanation. Teachers can be positive explainers and deliver information to their students in various ways, and students are passive receivers gather information through diverse channels. This is not only the most convenient, economical, and practical teaching model, but one that arts teachers favor and are acquainted with. Arts courses have scientific value, despite the transformation from diversified course to single course. Meanwhile, these courses have veered away from skill based courses to art and culture courses, now endowed with cultural value. We can understand the cultural value of arts' courses from two perspectives. First, that the arts are understood as a component of culture, and second, that the arts are grounded in the wider culture of society, which acts as an integral component of human culture. Therefore, learning about the arts is equivalent to cultural learning.

\subsection{Lack of Multiplicity in Programs}

$90 \%$ of music institutes offer classes that mainly focus on instrumental performance and relevant theory in class. However, a few offer other choices, such as technology, arts, poetry, language and other disciplines. Access to new forms of art is another crucial component to include. Not every student is skilled at producing Western classical arts, nor do all arts majors have artistic talents or an interest in arts theory. They need to find their own interests, performed using their own strengths, as many may be better suited to the development of specific types of arts only. For example, many students find it difficult to produce "Western Opera singing", as they are better suited to singing "pop songs or folk song. The new era is underpinned by information technology, and society's need for knowledge of diverse arts. Arts education, as developed alongside professional training is integral to a quality education; however, it might not enable students to fulfil the requirements for being a teacher in primary and secondary school. If college students are not fit to teach in schools, then they must be able to provide social arts services to realize their value, this way. Therefore, courses teaching arts multimedia production, choir rehearsals in the community, and pop arts are all necessary. Seeking new avenues in which to use the arts professionally is also valid; for example, if students also acquire a basic knowledge of psychotherapy, this can help them offer arts therapy within the domain of medical science.

Emphasis in contemporary society should also be placed on lifelong learning, professional competence, and self-education as core competences. We must ask every day "what knowledge should we learn today?", "what knowledge would help us grow?", "what capabilities should we nurture?"

\section{The Way Forward}

In summary, Chinese people have faced a variety of changes following fast market growth and adoption of a highly mobile form of society; this makes it unreasonable to emphasize "professional" at the expense of development. In terms of the arts, today's consumers prefer to have free choice, few wish to improve "Art promotion" of arts products, services and experiences. They are seeking something new. Obviously, a career as a professional artist is available to few individuals, making it important for researchers, policy makers, and course designers, to identify those directions with transformative potential, to broaden limited horizons to encompass the possible, thereby expanding the scope of educational change.

\section{References}

Brand, M. (2002). An ethnographic study of Hong Kong and American music education students. Contributions to Music Education, 29(2), 47-65.

Cao, L. (2000). Learning theories in music education. Beijing: Capital Normal University Press.

Guan, J. H. (2013). Cultural perspective of Chinese music aesthetic. Nanjing: Nanjing Normal University Publishing House.

Guo, S. J. (2012). Chinese arts education. Guangzhou: Jinan University Publishing House

Li, L., \& Zhao, F. (1996). International music education. Fuzhou: Fujian Music Publishing House.

Luo, X. P. (2003). The psychology of music education. Beijing: People Music House.

Ministry of Education of the People's Republic of China. (2008). National Standard in music education. Beijing: 
Beijing Normal University Publishing House.

Qin, R. M. (2009). The outline of core classes in higher education for musicians. Shanghai: Shanghai Education Publishing House

Wang, Y. H. (1995). Music education research. Fuzhou: Fujian Music Publishing House.

Xiu, H. L. (1998). The discussion in music aesthetic. The music research, 4.

Zhang, Q., \& Wang, C. Z. (1992). The foundation of music aesthetic. Beijing: People's Music Publishing House.

\section{Copyrights}

Copyright for this article is retained by the author(s), with first publication rights granted to the journal.

This is an open-access article distributed under the terms and conditions of the Creative Commons Attribution license (http://creativecommons.org/licenses/by/3.0/) 